\title{
ELISÉE RECLUS E O BRASIL
}

\author{
MILTON LOPES ${ }^{1}$
}

E aos que dos anarquistas fazem uma ideia tão falsa como horripilante, apresentamos a nobre e suave figura do bom semeador - um grande coração servido por uma grande inteligência.

Revista Aurora, apresentando artigo de Kropotkin sobre Reclus (São Paulo, set. 1905)

\section{A obra de Reclus chega ao Brasil}

As obras de Elisée Reclus começaram a ser mais difundidas entre os brasileiros a partir das três últimas décadas do século XIX - ao menos sua produção geográfica e científica, uma vez que no início da elaboração da Nouvelle géographie universelle, em 1875, seus editores proibiram, por contrato, que ele abordasse assuntos políticos ou religiosos em suas obras (ANDRADE, 1985:18). Monteiro Lobato é quem dá uma pista a respeito. Em carta ao amigo Godofredo Rangel (também escritor), a 20 de janeiro de 1904, Lobato (1959:50-52) escreveu a respeito da biblioteca do avô, o visconde de Tremembé, residente em Taubaté, no interior de São Paulo.

\begin{abstract}
A biblioteca de meu avô é ótima, tremendamente histórica e científica. Merecia uma redoma. Imagina que nela existem o Zend-Avesta, o Mahabarata e as obras sobre o Egito de Champollion, Maspero e Breasted; e o Larousse grande; e o Cantú grande; e o Elisée Reclus grande. (...) essa biblioteca, pela maior parte, fora de um filho de meu avô que depois de formar-se em São Paulo deu de correr mundo, andou pelo Egito e outros países históricos, apanhou febre na campanha romana e morreu num hotel de Nápoles. Secretário de legação. Sua bagagem veio para Taubaté, com os mais preciosos e curiosos livros comprados aqui e ali.
\end{abstract}

\footnotetext{
$1 \quad$ Jornalista, pesquisador do anarquismo, coordenador do Núcleo de Pesquisa Marques da Costa da Biblioteca Social Fábio Luz.
} 
Edgard Cavalheiro (1962:18), biógrafo de Lobato, nos informa que esse tio do escritor ainda se encontrava em Taubaté em 1887 antes de seguir a carreira diplomática e, portanto, de adquirir os livros que comporiam a biblioteca do visconde após seu falecimento. $\mathrm{O}$ fato de uma obra de Reclus chamar sua atenção no decorrer de suas viagens pela Europa, a ponto de considerá-la "preciosa e curiosa”, como a definiria mais tarde Lobato, demonstra que o nome do autor já não era estranho aos meios cultos da dita elite brasileira da época.

A presença da obra de Reclus no Brasil naquele período pode ser confirmada pelo fato de que aos 10 anos de idade, em 1878, o futuro escritor Graça Aranha, então em São Luís do Maranhão, utilizou os trabalhos de Reclus para a elaboração de um trabalho escolar. O pai de Graça Aranha, Temístocles, era um admirador dos escritos de Reclus, possuindo toda a obra do geógrafo anarquista em sua biblioteca. Mais tarde, instalaria um telescópio no terraço de sua casa e ministraria lições de astronomia ao filho, a partir de observações de Reclus (AZEVEDO, 2002:413-414). Não só a parte geográfica dos escritos de Reclus impressionaria Graça Aranha. Quando colaborava na Revista Brasileira publicação literária surgida no Rio em 1895, na qual começou a escrever a partir de janeiro de 1896 -, o escritor descreveu-se como "anarquista, por algum tempo sectário de Kropotkin e Elisée Reclus” (AZEVEDO, 2002:26). Antes de abandonar sua simpatia pelo anarquismo, Graça Aranha publicou em 1902 o romance Canaã, cujo enredo gira em torno do diálogo constante entre dois imigrantes alemães: um defensor de ideias autoritárias e o outro de teses libertárias. É curioso lembrar que os escritores que colaboravam na Revista Brasileira viriam a constituir o núcleo fundador da Academia Brasileira de Letras, que, recém-fundada, elegeria Reclus como membro correspondente a 25 de outubro de 1898, em sessão na qual estava presente Graça Aranha.

O francês era o segundo idioma de todos os que se pretendiam ilustrados naquela época, utilizado não só para a leitura, mas também para a conversação em salões, gabinetes e alcovas. E nem só de brasileiros que fossem ao exterior e trouxessem suas obras dependeria a difusão dos escritos de Reclus no país. A cultura francesa já deitara sólidas raízes em território verde-amarelo havia muitas décadas, desde que a corte de D. João VI se mudara para o Brasil. Como escreveu Gilberto Freire (1940:34):

Com a vinda para o Brasil, depois da chegada de D. João VI, de artistas, engenheiros, mestres, parteiras, comerciantes, 
cozinheiros, pasteleiros, modistas, retratistas, propagandistas de drogas, representantes de indústrias, e também de emigrados políticos ilustres, alguns até fidalgos, nasceu entre nós, de modo mais vigoroso, a influência da cultura e da técnica francesas.

Nesse quadro de irradiação da cultura gaulesa no Brasil, Freire (1940:84-85) destacou a difusão do livro francês no país, que

foi considerável durante a primeira metade do século XIX, avantajando-se o livro francês nos anúncios de jornais da época, ao livro latino e ao livro inglês. E não é só o livro francês de literatura, de filosofia, de política, que aparece com frequência naqueles anúncios: também o livro técnico, original ou traduzido.

Ainda nesse contexto é preciso ressaltar, sob o ponto de vista ideológico, a chegada ao Brasil de franceses refugiados da repressão à Comuna de Paris em 1871, como o libertário francês Gobley, que esteve preso com Elisée Reclus no forte de Quelern, na Bretanha. Gobley, depois de residir em Montevidéu e no Rio de Janeiro, fixou-se em Buenos Aires a partir de 1878 (NETTLAU, 1972:38).

Na perspectiva do contato de viajantes brasileiros com a obra de Reclus na Europa e da importação de seus trabalhos pelos livreiros de origem francesa, solidamente instalados num panorama cultural propício ao que de novo vinha da produção cultural e científica da França, é que devemos entender como se deu a recepção aos escritos geográficos de Reclus no Brasil por parte de uma elite econômica e intelectual e onde o movimento anarquista estava em seus primórdios ou simplesmente ainda não existia.

\section{Reclus vem ao Brasil}

O prestígio e o reconhecimento maior do trabalho puramente científico de Reclus pareceram ocorrer quando de sua vinda ao Brasil em 1893. Efetivamente, naquele ano

Reclus realizou sua última longa viagem para colheita de dados para suas obras. Além da Argentina, Uruguai e Chile, esteve também no Brasil. E é neste contexto que o vemos ser 
homenageado a 18 de julho de 1893 em sessão solene da Sociedade Geográfica do Rio de Janeiro, localizada em espaço atualmente ocupado pelo prédio da Escola Amaro Cavalcanti no Largo do Machado (então Praça Duque de Caxias). Das mãos do presidente daquela instituição, o Marquês de Paranaguá, Reclus recebeu o diploma de sócio honorário, a coleção da revista da instituição, o catálogo de sua biblioteca e arquivo, o relatório da Exposição Geográfica Sul-Americana e o trabalho relativo ao meteoro Bendengó, caído na Bahia e trazido para o Museu Nacional no Rio pela Sociedade (LOPES, 2004:37-38).

Discursando em resposta à homenagem, Reclus fez uma pequena palestra, em que procurou transmitir suas impressões sobre o Brasil, mostrando-se encantado com a paisagem natural do Rio de Janeiro e com seu clima (entusiasmo que também transparece em Estados Unidos do Brasil). Falou de sua admiração pelo sistema viário da cidade, que considerava tão desenvolvido quanto o de outras cidades do mundo. Lembrando que o Brasil fora o último país do hemisfério ocidental a abolir a escravidão, concluiu sua oração com uma reflexão crítica acerca dos brasileiros, afirmando que estes "geralmente não têm consciência de sua força e de seu valor. Eles possuem elementos para um desenvolvimento muito mais rápido do que aqueles que se notam nos mais adiantados países do Velho Mundo (CARDOSO, 2006).

Daí em diante, esse lado científico de Reclus passou à consagração definitiva e até institucional no Brasil. Em 1900 o editor Garnier do Rio, o principal do país àquela altura, publicou Estados Unidos do Brasil, extraído de sua Geografia universal, em tradução do barão de Ramiz Galvão e com comentários sobre o Contestado pelo barão do Rio Branco, então ministro do Exterior. Reclus tornou-se importante referencial de consulta para todos que estudavam a geografia do e no Brasil. Euclides da Cunha (1966:692), trabalhando como cartógrafo no Ministério do Exterior, ainda com o barão do Rio Branco à frente, anotou em carta ao escritor Coelho Neto a 30 de junho de 1908:

Elisée Reclus, Aires do Casal, Orville, Varnhagem, Pero Lopes, Capistrano (...) e todos os fazedores de mapas, e todos os melhores cronistas do século XVI são, com certeza, os sujeitos mais pacientes e sofredores deste mundo. Suportam- 
me! Aturam-me! Não se rebelam contra a minha curiosidade agressiva e insaciável!

Reclus não só tinha suas obras pesquisadas por integrantes do Ministério do Exterior do Brasil, como chegou ser contatado por seus diplomatas. Isso ocorreu alguns anos antes, em 1903, quando o Brasil estava envolvido em questão internacional com a Inglaterra em relação às fronteiras com a Guiana Inglesa. Procurado por autoridades brasileiras em Paris, Reclus aceitou o encargo de confeccionar e reproduzir cartas geográficas para a missão brasileira que cuidava do assunto. Na ocasião, afirmou que assim o fazia para se opor aos interesses imperialistas dos ingleses por uma passagem pelo Amazonas, onde pretendiam construir uma estrada de ferro (AZEVEDO, 2002:75-76). Mas não se pense que, por ser contra o expansionismo inglês nesse determinado momento, Reclus era apenas contra o imperialismo da Inglaterra. Décadas antes, em 15 de outubro de 1866, assinara um artigo na Revue des Deux Mondes, conceituada publicação cultural da época, sobre a Guerra do Paraguai, bastante desfavorável ao Brasil. Seu texto mereceu duas respostas em forma de editoriais no jornal Diário do Rio de Janeiro, a $1^{\circ}$ e 2 de dezembro daquele ano.

Mesmo aqueles que publicam "picaretagens” buscam em sua obra dados nos quais basear suas “armações”. Tal foi o caso do livro O Brasil em Haia, lançado em Londres em 1907 e assinado por William T. Stead, "figura secundária do jornalismo britânico e um papa-verbas diplomáticas”. O pretenso autor derramava-se em elogios à atuação de Rui Barbosa na Conferência Internacional de Haia naquele ano. Segundo Raimundo Magalhães Júnior (1965:288), o livro compunha-se de um texto, ditado

ao jornalista estipendiado, ou escrito diretamente pelo próprio Rui, que chegou a dar-lhe retrato com dedicatória, ou por seu sobrinho, Fernando Bandeira Dobbert (...) Outra parte foi recolhida de obras estrangeiras sobre o Brasil: de Percy F. Martin, Elisée Reclus, Alfred Russel Wallace, James C. Fletcher e Daniel P. Kidder.

O conceito de Reclus nos meios institucionais e acadêmicos no Brasil continuou acompanhando a trajetória que lhe cabia em sua própria

$2 \quad$ Ver carta de 6 de dezembro de 1866 de Henrique César Muzzio a Machado de Assis no Arquivo da Academia Brasileira de Letras. 
terra de origem, a França. No meio universitário francês, sua influência era pouco significativa e decresceu na segunda metade da década de 1920, quando se passou a dar maior atenção a Vidal de la Blache, que procurava desenvolver estudos monográficos regionais. La Blache estava também profundamente vinculado ao Estado, ao contrário, obviamente, de Reclus. Só 40 anos depois, a partir da década de 1960 e mais intensamente na de 1970, Reclus voltaria a ser lido e novamente conhecido nos meios acadêmicos e culturais franceses (ANDRADE, 1985:23-26). No Brasil, embora já se notem sinais de sua "recuperação" na universidade, ainda são necessários mais trabalhos que demonstrem sua atualidade não só como cientista "neutro", mas pela filosofia anarquista que orientava suas observações, estudos e escritos.

\section{Reclus e os anarquistas do Brasil}

O que acabamos de afirmar vem ao encontro do que pretendemos expor nesta segunda parte do texto. Abordaremos aspectos da difusão do pensamento de Reclus especificamente no contexto do movimento anarquista brasileiro, o que para ele talvez tivesse um significado bem maior do que sua glória acadêmica.

Em seu regresso à França, após sua visita ao Brasil, Reclus escreveu a um de seus genros, Paul Regnier, durante a travessia de Recife a Dacar a 5 de agosto de 1893. Abordando diversos aspectos de sua estada no Brasil, afirmou: "Há tanto, tanto para fazer neste país que farei uso certamente de meu crédito, se é que o há, para enviar para cá trabalhadores e pessoas de ideias, se a ocasião se me apresenta, e nada há de impossível neste sentido" (1943:260-261).

Acreditamos que essas "pessoas de ideias" a que se referia Reclus compreendessem também os anarquistas. O movimento anarquista no Brasil, quando dessa visita de Reclus, ainda estava em seu início, só tendo atividades estruturadas em São Paulo e no Paraná. No Rio, embora a polícia já houvesse detectado sinais de sua presença, sua organização só demonstraria sinais de vida alguns anos mais tarde. A imprensa anarquista editada e lida por esses pioneiros da anarquia no Brasil já publicava material de e sobre Reclus. Mas o acesso às suas obras para os militantes provavelmente era difícil, devido às barreiras criadas pelos idiomas e ao preço das obras, que certamente não era o melhor para os que se inseriam num movimento de e para trabalhadores. 
A barreira idiomática começou a cair quando foi lançada em Portugal, especificamente no Porto, em 1895, a primeira edição em português de A conquista do pão, de Kropotkin, com prefácio de Reclus. Impedido de ser reimpresso nos anos seguintes por força de um decreto emitido naquele mesmo ano em que a agonizante monarquia lusitana proibia qualquer atividade anarquista, o livro voltaria a ter edições em 1910 e 1913 pela Guimarães \& Cia. de Lisboa, dessa vez com tradução sob a responsabilidade de Manuel Ribeiro, então anarquista (KROPOTKIN, 1913:5-10, 1975:7-17). Os livros editados em Portugal eram de circulação corrente no Brasil, cujo parque editorial era bastante reduzido.

Outra importante contribuição para a divulgação do Reclus revolucionário foi a obra Socialismo libertário ou anarquismo: história e doutrina, de Silva Mendes, que veio à luz em Coimbra em 1896. A própria epígrafe desse extenso e bem-documentado trabalho é uma famosa frase de Reclus ("o dragão que está à entrada do palácio anárquico nada tem de terrível: é uma palavra apenas”), retirada de uma definição de Reclus para a palavra anarquia. No decorrer da exposição de Silva Mendes, Reclus está presente em capítulos como "O movimento teórico anarquista desde 1876 até a atualidade" (IV) e "A propaganda pelo fato" (V).

O estudo de Silva Mendes, que era uma tese para a Faculdade de Direito da Universidade de Coimbra, parece haver contribuído para o surgimento nos meios jurídicos brasileiros de uma corrente que propunha a "descriminalização" do anarquismo. Nessa linha de raciocínio, Evaristo de Moraes (pai) publicou no Rio de Janeiro, num dos primeiros números de seu Boletim Criminal Brasileiro, em 1900, o artigo "O anarquismo perante o direito penal", em que afirmava que a doutrina e a literatura anarquistas eram, como outras, dignas de estudo e mereciam ser discutidas, citando Reclus como uma dos autores de destaque dessa corrente de pensamento (MORAES, 1982:391-398).

O entendimento de Reclus como figura de importância para os anarquistas do Brasil parecia avançar. Em texto sobre o patriotismo incluído no opúsculo Rebeldias, a primeira obra de autor brasileiro a tratar do anarquismo -, Benjamim Mota (1898) exclama: "Quantas vezes muitos brasileiros que exaltam no sentimento patriótico não terão também, no foro íntimo, pensado que homens como Darwin, Haeckel, Verdi, Reclus ou Zola são mais seus compatriotas do que Prudente de Moraes, Campos Sales ou Manuel Vitorino?”. 
Ainda em 1898 o primeiro jornal anarquista a circular no Rio de Janeiro, $O$ Despertar, iniciava em sua terceira edição (a 3 de dezembro) a publicação do texto Ao meu irmão, o camponês, de autoria de Reclus. A imprensa anarquista brasileira sempre apreciou, a par da publicação de textos, citar frases de Reclus.

A edição de Estados Unidos do Brasil pela Garnier, em 1900, apesar de ser luxuosa e de problemática aquisição para operários em face de seu custo, não deixava de veicular tópicos do pensamento libertário de Reclus. Edgar Rodrigues (1969:28) destaca das observações de Reclus nesse livro o comentário de que os negros revoltados de Palmares "não seguiam tradições religiosas para o batismo dos que ali nasciam e os seus casamentos eram livres e regidos pelas 'leis da natureza' ”. O amor livre era um aspecto importante do pensamento e até da prática de Reclus. Seu primeiro casamento, a 14 de dezembro de 1858, foi realizado apenas no civil e desafiando os preconceitos de raça, já que se uniu com Clarisse Brian, nativa, como ele, da cidade de Sainte-Foy-la-Grande - filha de um capitão de navio e de uma mulher peul do Senegal -, com quem teve duas filhas, Magali e Jeanie. Viúvo em 1869, casou-se com a inglesa Fanny Lherminez. O segundo enlace teve como formalidade apenas a declaração dos dois interessados - perante as filhas de Reclus, seu irmão Elias, sua irmã Luísa e seu genro Dumesnil - de que se consideravam esposos (GIBLIN, 1986:28-38). Em 1882, coube-lhe pronunciar discurso por ocasião da união livre de suas filhas (RECLUS, 1973:45-50).

Por outro lado, também chamaram a atenção de Reclus movimentos sociais e populares da história do Brasil, como a Cabanada, por ele próprio definida como uma "guerra social de escravos contra senhores, de pobres contra ricos” (RODRIGUES, 1969:25). A Reclus também não escaparam os vínculos da nascente república com a "escola positivista de Augusto Comte” (RODRIGUES, 1969:33 e 70). Ainda em Estados Unidos do Brasil, Reclus dava notícia da fundação da colônia Cecília no Paraná. Ele já emitira sua opinião a respeito das colônias libertárias em 1889, em apêndice escrito para o livro A filosofia do anarquismo, de Charles Malato. Embora condenando a ideia de os anarquistas se apartarem da sociedade para a fundação de "paraísos fechados", admitia que no decorrer da luta social os anarquistas se agrupassem temporariamente, "praticando um novo modo de respeito mútuo e de completa igualdade” (RECLUS, 1978:131-136). 


\section{Traduções tornam obra de Reclus acessível a militantes}

Uma obra de Reclus economicamente acessível aos bolsos anarquistas só apareceria em português em 1904, quando o jornal $\mathrm{La}$ Tribuna Española, editado em São Paulo, lançou a tradução para o português da obra $A$ evolução, a revolução e o ideal anarquista (edição original francesa de 1897), o único trabalho exclusivamente político de Reclus. Quem o vertera para o português tinha sido o anarquista português Neno Vasco (1878-1920), que residiria em São Paulo de 1901 a 1911. Naquele ano Neno era responsável por uma das principais publicações ácratas brasileiras, o jornal $O$ Amigo do Povo. Neno chegou a corresponder-se com Reclus a propósito de sua tradução. Em carta de 3 de março de 1905, respondendo a correspondência de Neno Vasco, o geógrafo francês disse não se julgar habilitado para dar conselhos sobre a publicação da revista anarquista Aurora, que seria publicada em São Paulo no decorrer daquele ano. Na mesma carta, Reclus agradecia o envio de dois exemplares da tradução de seu livro, pensando em dá-los a algum amigo português que passasse pela França. Procurando atender a um pedido de Neno sobre colaboração, Reclus afirmou haver terminado um artigo de maneira superficial e que poderia enviá-lo para o Brasil, reservando-se o direito de ampliar o texto para ser reproduzido em outra publicação. Com o falecimento de Reclus a 4 de julho daquele ano, seria a revista Aurora que reproduziria (nos números 8 e 9, setembro e outubro de 1905) artigo biográfico-necrológico de autoria de Kropotkin sobre Reclus. O artigo era precedido de uma "Nota da Redação", de que transcrevemos um pequeno trecho na epígrafe deste texto. Na mesma edição, Aurora anunciava haver recebido prospecto da versão em espanhol (de Anselmo Lorenzo) para $O$ homem e a terra, de Reclus. Semanalmente seria publicado um fascículo de 24 páginas, que poderia ser adquirido por 50 cêntimos de peseta por pedido direto a Alberto Matín (Apartado de Correos, 266 - Barcelona) ou por intermédio da redação de Aurora.

A partir da tradução de Neno Vasco para o livro de Reclus, a difusão de seus escritos em língua portuguesa ocorreu mais rapidamente, inicialmente orientada pelo jornal A Terra Livre. Ainda em 1908 a biblioteca daquele periódico anunciou ter o livro à venda, assim como a obra A anarquia e a Igreja (1907), escrita em parceria com G. Guyot, em meio a títulos de outros autores. No caso desse folheto, tratava-se de uma edição portuguesa de texto inicialmente publicado no jornal anarquista francês Temps Nouveaux, em 1900, e editado em formato de livreto nas Publications des Temps Nouveaux, no ano seguinte. É interessante destacar 
que as obras de Reclus lançadas em Portugal começaram a chegar ao Brasil, também contribuindo para maior divulgação de seus textos no país. Assim, A anarquia e a Igreja teve nova edição em português em 1924 (Editorial Anarquista); também na década de 1920 publicou-se, pela biblioteca Nova Aurora do Porto, A evolução legal e a anarquia; o texto Ao meu irmão, o camponês teve duas edições: em 1909 (Publicações O Protesto, Lisboa) e em 1913 (Biblioteca de A Vida, Porto, 1913) (FREIRE, J., 1992:392-416).

\section{Reclus e a educação libertária no Brasil}

Como consequência da difusão de suas ideias entre os anarquistas brasileiros, estes tiveram oportunidade de homenagear Reclus até como colaborador da escola moderna de Ferrer, para a qual tinha escrito textos visando especificamente à instrução de seus alunos. Em 1906 foi fundada em Porto Alegre, por militantes anarquistas da cidade, a Escola Elisée Reclus. Inicialmente as atividades eram direcionadas para a categoria profissional dos marmoristas. Tinha uma sala de leitura com livros e jornais em diversos idiomas e constituiu-se logo no princípio como um curso de estudos livres, nos moldes das experiências das universidades populares. Segundo o jornal anarquista de Porto Alegre A Luta, em 16 de setembro de 1906, "cada um ensinando o que sabe e procurando cada qual aprender o que ignora, à noite reúnem-se ali aqueles moços, mantendo palestras interessantes, das quais sempre se sai aprendendo alguma coisa de novo”. Com uma programação que incluía matérias como esperanto, francês, português, matemática, história geral, do Brasil e social, desenho, educação física, economia política, geografia, física, química, história natural e anatomia, a Escola Elisée Reclus teve em 1907 como agregado um grupo filodramático de teatro social, que montou o drama antimilitarista Avatar, do escritor e jornalista anarquista gaúcho Marcelo Gama. Nem a saída de vários de seus integrantes em 1909 acabou com a escola. Reformulada, continuou funcionando e em 1911 localizava-se na sede da União Operária em Porto Alegre (MARÇAL, 1985:65-68).

\section{Reclus e os intelectuais anarquistas brasileiros}

Entre os intelectuais que aderiram ao anarquismo a partir do início do século XX, a marca de Reclus foi bem forte. Tal parece ter acontecido de 
maneira mais intensa com o escritor mineiro Avelino Foscolo (1864-1944), que alguns anos antes de sua morte declarava em Belo Horizonte ao também escritor Eduardo Frieiro: "Quanto aos meus princípios de filosofia social sou ácrata, como o foram Tolstoi, Elisée Reclus, Jean Grave...” (FRIEIRO, 1979:19).

Em verdade, o interesse de Foscolo por Reclus parece ter sido despertado pela edição de Estados Unidos do Brasil pela Garnier em 1900. $\mathrm{O}$ interesse foi aumentando até que as obras de Reclus sobre geografia se tornassem uma das leituras favoritas do escritor. Fatores de identificação de Foscolo com Reclus poderiam ser encontrados pela importância que o geógrafo francês conferia a Minas Gerais no panorama nacional e à crítica à mania dos brasileiros de jogos de azar, também criticada por Foscolo em seu romance A capital. Outros possíveis elos entre Foscolo e Reclus seriam a importância de solucionar o problema da devastação e do cultivo irracional do solo e a denúncia do lamentável estado da instrução pública. Tais fatos são apontados por Regina Horta Duarte (1991:59-60), em sua biografia de Foscolo, como alguns dos pontos a unir o pensamento do escritor mineiro e o do geógrafo francês. Duarte levanta a hipótese de um encontro entre os dois quando da visita de Reclus a Minas em 1893.

Também mineira, Maria Lacerda de Moura (1887-1945) era professora e, talvez por isso, não tenha deixado de chamar a atenção para a colaboração de Reclus com Ferrer num de seus primeiros livros, Renovação (MOURA, 1919:249). Alguns anos depois, em 1924, em A mulher é uma degenerada, ela afirma ser Reclus, como outros, um verdadeiro revolucionário que "não se vende, não se mutila para vencer, não se presta a papéis deprimentes, cria dentro de si mesmo a sombra do ideal, renovando, a cada instante, os votos de fé no alvorecer de outros sonhos e caminha desassombradamente pela floresta densa dos preconceitos sociais” (MOURA, 1932:172). Moura (1932:174) enfatiza o papel dos revolucionários, considerando Reclus um verdadeiro rebelde: “o grande Reclus, o santo, o filósofo, o sábio”. Além de rebelde, Reclus seria para a autora um estoico, como Sócrates, Kropotkin, Ibsen e Han Ryner, dignos de admiração por serem raros:

Como são raros os velhos de almas sãs para penetrar o sentido da vida, de almas jovens para desejar e continuar a realização interior pela bondade envolvente, tolerantes, compreensivos para deixar aos moços a liberdade de pensar, de errar, de aprender, de adquirir experiências próprias, de viver segundo 
as suas necessidades e seus sonhos precursores (MOURA, 1931:23).

O preço que figuras como Reclus pagariam pela boa palavra que difundiam seria a de que esta fosse considerada letra morta, já que:

a Igreja, monopolizadora da educação, e o Estado, seu cúmplice, e o Capital, grande acionista dessa extraordinária Companhia Anônima Ilimitada, todos se entendem maravilhosamente para massacrar a liberdade de consciência e cultivar até o infinito a imbecilidade e o encarneiramento humano (MOURA, s/d:42-43).

Na linha de combate que adotou de abrir consciências opondo-se aos que desejavam o embrutecimento humano, Moura lançou na década de 1930 Fascismo: filho dileto do capital e da Igreja, em que afirma não poder se admirar da "tendência escravocrata da igreja, cuja hierarquia de castas e posição social estabelece privilégios odiosos - para maior glória do clero" (s/d:42-43). Para ilustrar seu raciocínio, cita que "a obra de Elisée Reclus (O homem e a terra), na tradução espanhola de A. Lorenzo, traz uma gravura representando um circo onde os conquistadores espanhóis do Peru tinham presas as suas matilhas de cães, os quais eram alimentados com carne de índios” (s/d:42-43). Num ensaio sobre a filosofia socrática para a tradução que fez da Apologia de Sócrates, de Platão, em 1936, Moura (s/d) situa Reclus numa linhagem de pensadores de que um dos antepassados seria Platão.

\section{Reclus e Lima Barreto}

Já para o escritor carioca Lima Barreto (1881-1922), Reclus era um autor que devia ser lido pelos que se interessavam por "coisas sociais". Nesse sentido, inclui seu nome entre os dos autores cujas "brochuras boas e baratas em espanhol, português e francês” pretendia mandar ao escritor Jaime Adour da Câmara, natural do Rio Grande do Norte, em carta de 27 de julho de 1919. Câmara então residia em Natal (LIMA BARRETO, 1956:170-171). Amante não só do estudo das "coisas sociais", mas também das "coisas cariocas”, Lima Barreto, na abertura do conto "O moleque” (1920), nota que 
Reclus, na sua Geografia universal, tratando o Brasil, notava a necessidade de conservarmos os nomes tupis dos lugares de uma terra. Têm eles, diz o grande geógrafo, a vantagem de possuir quase todos um sentido muito claro, nas suas palavras, exprimindo algum fato da natureza, a cor das águas correntes, a altura, a forma ou o aspecto dos rochedos, a vegetação ou a aridez da região. No Rio de Janeiro há de fato nomes tupis tão eloquentes para traduzir a forma ou o encanto dos lugares que ficamos pasmos quando lhes sabemos a significação, com o poder poético, com a força de emoção superior de que eram capazes os primitivos canibais habitantes desta região, diante dos aspectos da natureza tão bela e singular que é a que cerca e limita nossa cidade (LIMA BARRETO, 1956:36).

O poeta santista Martins Fontes (1884-1937), embora admirador exaltado de Kropotkin, considera em seu soneto "Ululo” que "herói é só quem faz que a razão se ilumine/e, para outrem vivendo. Almas apostolares, é um Proudhon, é um Reclus, é um Pedro Kropotkin” (PENTEADO, 1968:172). Num ensaio sobre Eça de Queirós incluído em seu livro Terras da fantasia, Martins Fontes (1933:130) afirma que "só a anarquia de Kropotkin ou de Reclus nos satisfaz e consola e sobreleva, super-humanizando-nos”. Para Martins Fontes (1937:83), um dos fatores a alimentar sua admiração por Kropotkin era que "Reclus o adorava. Com ele conviveu muitos anos sem nunca lhe encontrar um defeito, uma falha”. Em outro trecho de um ensaio sobre Kropotkin, registra: "Louise Michel Élie Reclus - Elisée Reclus, Trindade do nosso Amor!” (1937:90). Escreve na bibliografia relativa a esse texto: "Palavras de um Revoltado Kropotkin - anotadas e prefaciadas pelo amado Elisée Reclus” (1937:10). Fontes dedica poema em seu livro Sombra, silêncio e sonho (1933:99-100) aos três irmãos Reclus: Élie, Onésime e Elisée. Finaliza dizendo que “o período em que vivo me apaixona!/ Vejo a maré montante vir à tona/ o mistério do pélago iracundo.../ E sonho, ao resplendor do meio-dia, ao realizar-se a benção da Anarquia, o sol do amor pacificando o mundo”.

Em 1963 uma editora anarquista do Rio, a Mundo Livre, lançou a coletânea Anarquismo: roteiro de libertação social, organizada por Edgard Leuenroth (1963). Entre os textos escolhidos, estavam "Tudo muda: na vida física e na vida social” e "Palavra que fere preconceitos", de Reclus. Teria Leuenroth, ao incluir escritos de Reclus naquela antologia, recordado seu julgamento em janeiro de 1918 no Tribunal do Júri de São Paulo? 
Acusado de incitar ao roubo os grevistas de 1917 naquela cidade, seu principal defensor, Evaristo de Moraes, citou o livro Socialismo libertário ou anarquismo, de Silva Mendes, em que o autor português faz menção a Elisée Reclus como uma das maiores individualidades daquele momento histórico e que, portanto, "ninguém se deslustra em ser anarquista". Leuenroth foi absolvido.

\section{ELISÉE RECLUS E O BRASIL}

Resumo: O artigo discute como a obra de Elisée Reclus (1830-1905), geógrafo e militante anarquista francês, alcançou o Brasil. Em primeiro lugar, é considerado o aspecto científico de sua produção, que chegou ao país a partir das três últimas décadas do século XIX. A seguir, é descrito como seus textos de caráter político também influenciaram, no Brasil, militantes e intelectuais.

Palavras-chave: Reclus; anarquismo; geografia; Brasil.

\section{ELISÉE RECLUS AND BRAZIL}

Abstract: The work of Elisée Reclus (1830-1905) start to be introduced in Brazil at the last three decades of the nineteenth century. His anarchist writings, however, would be translated into Portuguese just with the beginning of the twentieth century. This article discuss the relation between his intelectual legacy and his political influence in Brazil.

Keywords: Reclus; anarchism; geography; Brazil.

\section{BIBLIOGRAFIA}

ANDRADE, Manuel Correia de (1985). Elisée Reclus. São Paulo: Ática. ARANHA, Graça (1969). Canaã. 12. ed. Rio de Janeiro: F. Briguiet \& Cia. Editores.

AZEVEDO, Maria Helena Castro (2002). Um senhor modernista: biografia de Graça Aranha. Rio de Janeiro: Academia Brasileira de Letras.

CARDOSO, Lucienne P. Carris (2006). A visita de Elisée Reclus à Sociedade de Geografia do Rio de Janeiro. Revista da Sociedade Brasileira de Geografia, v. I, n. 1. 
CAVALHEIRO, Edgard (1962). Monteiro Lobato: vida e obra. 3. ed. São Paulo: Brasiliense. v. 1.

CUNHA, Euclides da (1966). Obra completa. Rio de Janeiro: Aguilar. v. 2.

DUARTE, Regina Horta (1991). A imagem rebelde. Campinas: Pontes.

FREIRE, Gilberto (1940). Um engenheiro francês no Brasil. Rio de Janeiro: José Olympio.

FREIRE, João (1992). Anarquistas e operários. Lisboa: Afrontamento.

FRIEIRO, Eduardo (1979). O romancista Avelino Foscolo. In: FOSCOLO, Avelino. A capital. 2. ed. Belo Horizonte: Conselho Estadual de Cultura de Minas Gerais.

GIBLIN, Béatrice (1986). Elisée Reclus: el hombre y la tierra. México: Fondo de Cultura Económica.

KROPOTKIN, Pedro (1913). A conquista do pão. 3. ed. Lisboa: Guimarães \& Cia,

. (1975). A conquista do pão. 4. ed. Lisboa: Guimarães \& Cia.

LEUENROTH, Edgard (Org.) (1963). Anarquismo: roteiro de libertação social. Rio de Janeiro: Mundo Livre.

LIMA BARRETO (1956). Correspondência ativa e passiva. São Paulo: Brasiliense. v. 2.

. (1956). Histórias e sonhos. São Paulo: Brasiliense.

LOBATO, Monteiro (1959). A barca de Gleyre. 9. ed. São Paulo: Brasiliense. v. 1.

LOPES, Milton (2004). Crônica dos primeiros anarquistas no Rio de Janeiro (1888-1900). Rio de Janeiro: Achiamé.

MAGALHÃES JÚNIOR, Raimundo (1965). Rui: o homem e o mito. Rio de Janeiro: Civilização Brasileira.

MARÇAL, João Batista (1985). Primeiras lutas operárias no Rio Grande do Sul. Porto Alegre: Globo.

MARTINS FONTES. (1933). Sombra, silêncio e sonho. São Paulo: Elvino Pocai.

. (1933). Terras da fantasia. Santos: Instituto D. Escolástica Rosa.

. (1937). Fantásticas. São Paulo: Empresa Editora J. Fagundes.

MORAES, Evaristo de (1982). O anarquismo no Tribunal do Júri. Revista Forense, v. 279. 
MOTA, Benjamim (1898). Rebeldias. São Paulo: Tipografia Brasil de Carlos Gerke \& Cia.

MOURA, Maria Lacerda de (1919). Renovação. Belo Horizonte: Atheme. . (1931). Civilização: tronco de escravos. Rio de Janeiro: Civilização Brasileira.

(1932) A mulher é uma degenerada. 3. ed. Rio de Janeiro: Civilização Brasileira.

. (s/d). Apêndice. In: PLATÃO. Apologia de Sócrates. 3. ed. São Paulo: Atena.

. (s/d). Fascismo: filho dileto do capital e da Igreja. São Paulo: Editorial Paulista.

NETTLAU, Max (1972). Viaje libertaria por la America Latina. Reconstruir: Revista Libertaria, Buenos Aires, n. 76.

PENTEADO, Jacob (1968). Martins Fontes: uma alma livre. São Paulo: Livraria Martins Editora.

RECLUS, Elisée (1900). Estados Unidos do Brasil: geografia, etnografia, estatística. Rio de Janeiro; Paris: H. Garnier Livreiro Editor.

. (1943). Correspondência (de 1850 a 1905). Buenos Aires: Imán.

. (1973). La Union Libre. In: El amor libre: la revolución sexual de los anarquistas. Buenos Aires: Rodolfo Alonso Editor.

. (1978). Las colonias libertarias. In: MALATO, Carlos. Filosofia del anarquismo. Madri: Júcar.

RECLUS, Elisée; GUYOU, G. (1907). A anarquia e a Igreja. Lisboa: Novos Horizontes.

RODRIGUES, Edgar (1969). Socialismo e sindicalismo no Brasil. Rio de Janeiro: Laemmert.

SILVA MENDES, Manuel da (s/d). Socialismo libertário ou anarquismo: história e doutrina. 2. ed. Lisboa: Letra Livre. 